\title{
Structure of Golgi Transport Proteins
}

\author{
Daniel Kümmel and Karin M. Reinisch \\ Department of Cell Biology, Yale University School of Medicine, New Haven, Connecticut 06520 \\ Correspondence: karin.reinisch@yale.edu
}

The function of the Golgi has long been recognized to critically depend on vesicular transport from, to, and within its cisternae, involving constant membrane fission and fusion. These processes are mediated by Arf GTPases and coat proteins, and Rabs, tethers and SNARE proteins, respectively. In this article, we describe structural studies of Golgi coats and tethers and their interactions with SNAREs and GTPases as well as insights regarding membrane traffic processes that these have provided.

\section{GRASP PROTEINS}

G RASP55 and GRASP65 (Golgi ReAssembly Stacking Protein) are required for proper cisternal stacking (Barr et al. 1997; Shorter et al. 1999), and their knockdown leads to fragmentation of the Golgi (Xiang and Wang 2010). Their phosphorylation during the cell cycle results in Golgi ribbon unstacking just prior to mitosis (Feinstein and Linstedt 2008; Sengupta and Linstedt 2010).

GRASP proteins are amino-terminally myristoylated for membrane attachment (Sengupta et al. 2009). They are composed of two tandem PDZ domains, followed by an extended region $(\sim 30 \mathrm{kDa})$ that is predicted to be unstructured. The crystal structure of GRASP55 reveals a tandem arrangement of two circularly permutated PDZ domains, each with a peptide binding groove (Truschel et al. 2011). Mutational data suggest that the peptide binding groove of PDZ2 mediates Golgi association via interactions with the golgin GM130 (Barr et al. 1998) (or golgin-45 for GRASP65) (Kuo et al. 2000; Short et al. 2001), whereas PDZ1 is important for multimerization to effect Golgi stacking (Wang et al. 2005; Sengupta et al. 2009). It was proposed that the stacking mechanism involves both PDZ domains and that a loop near the carboxyl terminus of PDZ2 binds in the peptide binding groove of PDZ1 of a second GRASP molecule (Truschel et al. 2011), allowing for oligomerization of the GRASP domains (Fig. 1A). The interaction between the PDZ2 loop and the PDZ1 domain was not observed in the crystal structures, but this may have been caused by crystal packing constraints (Truschel et al. 2011). The GRASP domain with a phospho-mimetic mutation known to disrupt stacking was also crystallized, and a small conformational change was observed in the PDZ2 loop, perhaps sufficient to prevent its binding to PDZ1. Thus, the findings provide a model that helps explain the molecular basis of cisternal stacking of the cis and medial Golgi by GRASPs and its disassembly during mitosis.

Editors: Graham Warren and James Rothman

Additional Perspectives on The Golgi available at www.cshperspectives.org

Copyright (C) 2011 Cold Spring Harbor Laboratory Press; all rights reserved; doi: 10.1101/cshperspect.a007609

Cite this article as Cold Spring Harb Perspect Biol 2011;3:a007609 
D. Kümmel and K.M. Reinisch

A

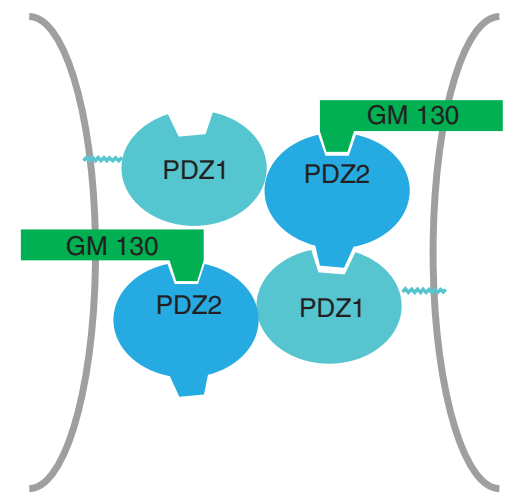

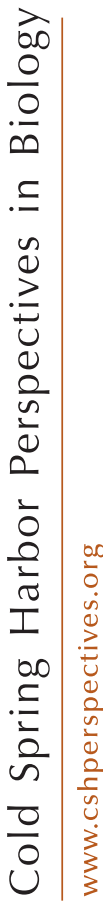

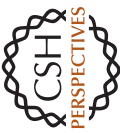

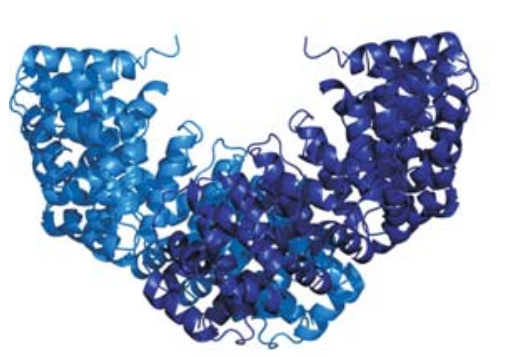

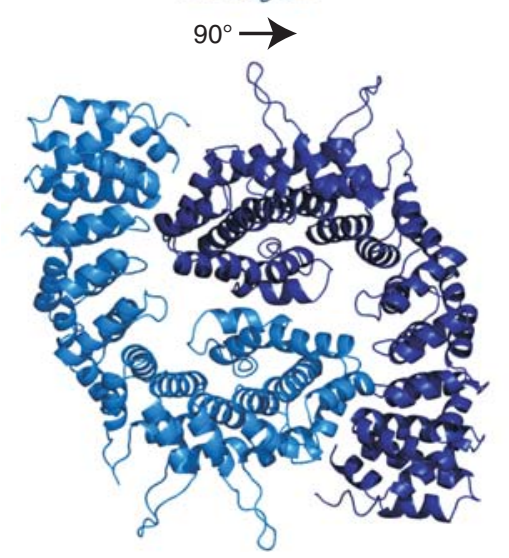

C
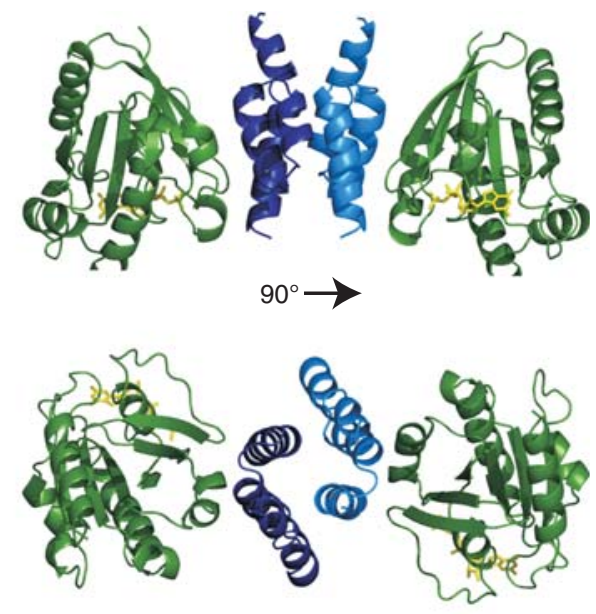

D

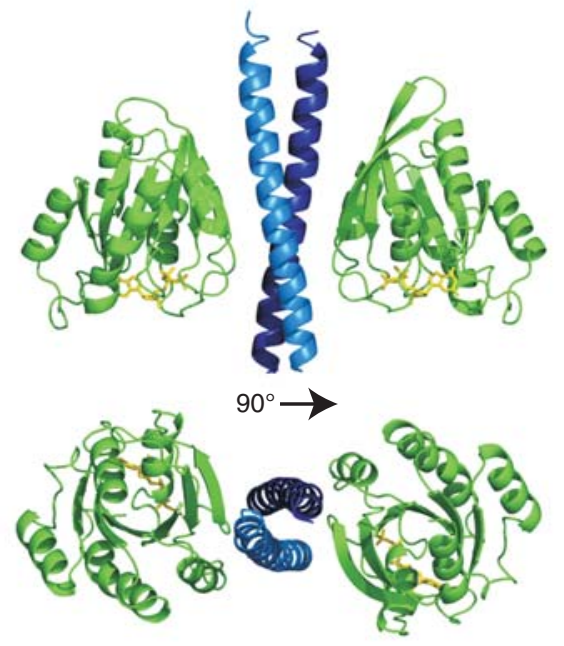

Figure 1. Structures of Golgi tethers. (A) The GRASP domain is composed of two tandem PDZ domains. An internal PDZ ligand in PDZ2 binds to PDZ1, suggesting a model for oligomerization of GRASPs. $(B)$ The globular head domain of p115 adopts an armadillo-like fold. A crystallographic dimer, likely to resemble the configuration in solution, is shown (PDBID 2W3C). (C) The GRIP domain of golgin-245 (blue) in complex with the GTP (yellow) bound form of Arl1 (green) (PDBID 1R4A). (D) A short coiled-coil segment of GCC185 (blue) bound to GTP (yellow) Rab6 (green) (PDBID 3BBP).

\section{GOLGINS}

The golgins constitute a diverse group of Golgi associated proteins that play a role in Golgi stacking, vesicle tethering, and constitution of the Golgi matrix (Short et al. 2005). Golgins are characterized by an extended coiled-coil region that mediates homodimerization. They also interact with one another and GTPases of the Rab, Arf, and Arl families, both through binding sites in the coiled-coil or via additional domains. Based on these specialized domains, golgins can be grouped into different classes.

p115 (Uso1 in yeast), which tethers ERderived vesicles to the cis-Golgi, is one of the best studied golgins (Sapperstein et al. 1995; 
Levine et al. 1996; Nakamura et al. 1997). Electron microscopy studies revealed that the amino terminus of p115 forms a globular domain and that the carboxyl terminus dimerizes to form a $\sim 45 \mathrm{~nm}$ long parallel coiled-coil tail (Sapperstein et al. 1995; Yamakawa et al. 1996). The tail is extended, but has several kinks, indicating that the coiled-coil packing is not continuous along its entire length (Yamakawa et al. 1996). An important implication of this finding is that $\mathrm{p} 115$, and golgins in general, are not necessarily rigid rods but might bend.

Several crystal structures have been determined for the p115 amino-terminal head domain (An et al. 2009; Striegl et al. 2009). It has an armadillo-like fold, in which 11 triplehelical motifs, named tether-repeats (TRs), are arranged into a solenoid (Fig. 1B). The aminoterminal TR contains four rather than three $\alpha$ helices and mediates dimerization within the crystal (Striegl et al. 2009). The p115 constructs that were crystallized lacked the coiled-coil regions and behave as monomers in solution, so that the dimer interface may represent a crystallization artifact. However, the presence of such an interface is consistent with the formation of a parallel coiled-coil tail and may also reflect how the head domains associate in dimers of full-length p115.

Interactions have been identified between p115 and a number of other key proteins involved in traffic to the Golgi. The aminoterminal TR in the p115 head domains interacts with active, membrane-bound Rab1, likely serving to anchor p115 to the membrane (Allan et al. 2000; An et al. 2009). This interaction has been proposed to tether COP II vesicles to each other in homotypic vesicle fusion (Bentley et al. 2006). The amino-terminal head domain also interacts with the COG membrane tethering complex (Sohda et al. 2007), and with the $\beta$-COP subunit in coatomer (Guo et al. 2008). The coiled-coil tail interacts the $\mathrm{v}$-SNARE GOS28 and the t-SNARE syntaxin-5 (Bentley et al. 2006; Shorter et al. 2002), and an acidic region carboxy-terminal to the coiled-coil binds to GM130 and giantin, two further Golgilocalized coiled-coil tethers, to link p115 to the cis-Golgi (Beard et al. 2005).
The GRIP domains present at the carboxyl terminus of many golgins mediate binding to the Arf-like GTPase Arll and function in recruiting these golgins to the trans-Golgi (Setty et al. 2003). GRIP-domain golgins include GCC185, GCC88, golgin-97, and golgin-245 (Short et al. 2005). The GRIP domain of golgin-245 was crystallized in complex with GTP-bound Arl1 (Panic et al. 2003a; Wu et al. 2004). The GRIP domain comprises three antiparallel $\alpha$-helices and forms a homodimer (Fig. 1C). Each GRIP domain binds one Arl1 molecule via interactions of the two aminoterminal helices with the switch1-interswitchswitch2 surface of the GTPase, where the switches are the regions that differ in the GDP- and GTP-bound forms of a GTPase. A highly conserved tyrosine residue in the GRIP domain is inserted into a selectivity pocket present only in the GTP-bound form of Arl1. Arl1 contains a myristoylation site and an amphipathic helix and GRIP domains have aromatic surface residues, which may all serve for membrane association (Panic et al. 2003a). In the tetrameric Arl1/GRIP complex, these interactions likely cooperate to mediate stable Golgi binding.

The golgin GCC185 is recruited to the Golgi via its GRIP domain but independently of Arl1, suggesting that a different GTPase is the physiological binding partner of GCC185 in vivo (Derby et al. 2007; Houghton et al. 2009). Given that residues at the GTPase interaction surfaces of different GRIP domains are not absolutely conserved, it would not be surprising if GRIP domains were able to interact with Arf or Arl GTPases other than Arl1.

In this context, it is interesting to note that golgin GMAP210 contains a GRAB domain, which is closely related in sequence to the GRIP domain but mediates binding to Arf1. In GRAB domains, the conserved tyrosine in GRIP, which mediates interactions with Arl1, is replaced by leucine or a branched, apolar residue, apparently shifting substrate specificity to Arf GTPases (Gillingham et al. 2004). Another interesting feature of GMAP2 10 in particular is the presence of an amino-terminal ALPS (amphipathic lipid-packing sensor) motif, 
which intercalates into curved but not flat membranes (Drin et al. 2007). Thus, GMAP210 is thought to interact with Arf1 marked Golgi membranes via its carboxyl terminus while binding vesicles with its amino terminus, with its coiled-coil spanning $\sim 200 \mathrm{~nm}$ between (Drin et al. 2008).

Some golgins are also directly bound to the Golgi membrane through single trans-membrane helices. These include Giantin and golgin-84 (Linstedt and Hauri 1993; Linstedt et al. 2000; Diao et al. 2003), which contribute to the complex Golgi matrix network by interacting with Rab GTPases and other golgins.

Even after extensive research on the golgins, the role, or maybe multiple roles, of their extended coiled-coil domains remains unresolved. The coiled-coil domains have generally been thought of as rigid rods that extend away from the Golgi, surveying the Golgi periphery for binding partners. However, the predicted coiled-coil propensity in these regions varies, with coiled-coil segments interrupted by unstructured regions that would allow the proteins to bend or even collapse like an accordion. This idea is supported by observations in the electron micrographs of $\mathrm{p} 115$, as discussed above (Yamakawa et al. 1996). Based on weak sequence similarity, it has also been suggested that the coiled-coil domains of several golgins might be interrupted by tether repeats related to the armadillo-like repeats in the globular head domain of p115 (An et al. 2009). The length of the coiled-coil domains of many golgins is enormous: in both giantin and Uso1, for example, they are $\sim 150 \mathrm{~nm}$ long (Yamakawa et al. 1996; An et al. 2009). Thus, these golgins would be able to tether incoming vesicles at very long distances.

Many golgins also have multiple GTPase binding sites along the length of their coiledcoil domains (Beard et al. 2005; Sinka et al. 2008; Hayes et al. 2009). This would be consistent with a tentacular model of the Golgi, as proposed by Munro and colleagues (Sinka et al. 2008), in which the golgins extend out from the Golgi in a dense network. The tethers would capture incoming vesicles via interactions with vesicle-bound GTPases at the periphery of this network, and the vesicles would then "hop" toward the Golgi by binding to successive GTPase binding sites. However, the finding of multiple GTPase binding sites per coiled-coil domain also fits the notion that golgins might be involved in stabilizing Golgi structure by linking Golgi cisternae (Hayes et al. 2009). In this model, the golgin is aligned between two cisternae and bridges them by binding GTPases on both their surfaces. The structure of Rab6 in complex with a short fragment of GCC185 may provide the molecular basis for these interactions (Burguete et al. 2008). The crystallized fragment of GCC185 is a helix that forms a parallel dimer, which binds two Rab6 molecules (Fig. 1D). The interaction is between a hydrophobic triad in the Rab6 switch1-switch2 region with two aliphatic residues in GCC185, conferring specificity for GTP-Rab/effector interaction. Recent in vivo data suggest that this interaction with Rab6 does not play a role for GCC185 function in cells (Houghton et al. 2009), but it is plausible that a different Rab might bind this site under physiological conditions. Likely, the mode of binding is representative for other Rab/golgin interactions.

\section{CATCHR COMPLEXES}

A number of multisubunit tethering complexes (MTCs) have been implicated in the regulation of membrane trafficking as tethering factors. The CATCHR (Complex Associated with Tethering Containing Helical Rod) family of tethers was first identified based on weak sequence homology in the amino terminus of their subunits, which contain an amphipathic helix that is predicted to form a coiled-coil (Whyte and Munro 2001, 2002). Structural studies revealed that CATCHR subunits also share a "helical rod"-fold, hinting at a divergent evolution of these complexes from a common progenitor (Yu and Hughson 2010). Four family members have been described: the hetero-octameric exocyst acts at the plasma membrane, the Dsll complex contains three subunits and is found at the endoplasmic reticulum, and another hetero-octameric complex COG (Conserved 
Oligomeric Golgi) and the tetrameric GARP (Golgi-associated retrograde protein) complex are both localized to the Golgi.

The GARP complex (also named VFT, Vps fifty-three complex) is involved in retrograde transport from endosomes to the late Golgi (Conibear and Stevens 2000). GARP contains four subunits (Vps51, Vps52, Vps53, and Vps54). Carboxy-terminal fragments of the GARP subunits Vps53 and Vps54 have been crystallized, showing that these proteins consist of helical rods arranged in tandem, the fold characteristic for CATCHR subunits (Fig. 2A). A conserved surface patch that is essential for retrograde traffic was identified in Vps53 (Vasan et al. 2010), and the structure of Vps54 (PerezVictoria et al. 2010a) provides the molecular basis of the wobbler mouse phenotype which causes spinal muscular atrophy and defective spermiogenesis (Schmitt-John et al. 2005). The mutation of leucine 967 to glutamine disrupts the hydrophobic core of the protein, leading to lower protein stability in vitro and reduced Vps54 levels, and consequently GARP levels, in vivo (Perez-Victoria et al. 2010a).

In contrast to the human ortholog Ang2 (Perez-Victoria et al. 2010b), yeast Vps51 is small, containing an amino-terminal coiled-coil region but lacking the helical rod domain found in other CATCHR subunits (Conibear et al. 2003). Ang2/Vps51 mediates the interaction of GARP with the regulatory Habc domain of the endosomal t-SNARE Syntaxin6 and Tlglp, respectively (Perez-Victoria et al. 2010b; Siniossoglou and Pelham 2002), though this interaction is not essential for vesicle docking or fusion (Fridmann-Sirkis et al. 2006). The structure of a 20-residue peptide from the Vps51 amino terminus in complex with the Habc domain of Tgll is to date the only interaction of a tether with the fusion machinery characterized at an atomic level (Fig. 2B). The Vps51 fragment is partially $\alpha$-helical and aligns alongside Tgll in a groove between two of the Habc helices distinct from the binding site for the SNARE motif. This binding mode may well be conserved in other SNARE-CATCHR interactions, as the Dsl1 and COG complexes also interact with the Habc domains of their SNARE partners (Shestakova et al. 2007; Ren et al. 2009).

Interaction partners of GARP also includes GTPases. In yeast, Vps53 is an effector of Arl1 (Panic et al. 2003b) and Vps52 is an effector of Ypt6 (Siniossoglou and Pelham 2001). This last interaction is conserved in mammals as
A

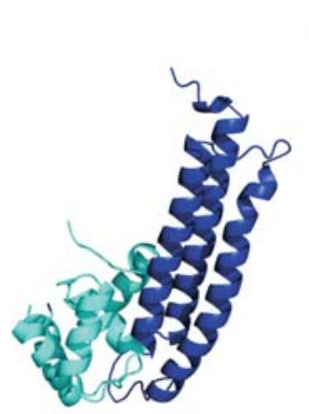

Vps53

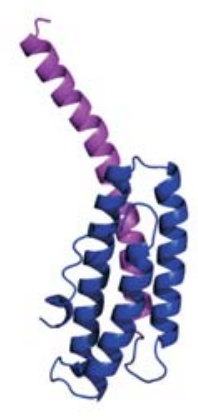

Vps54

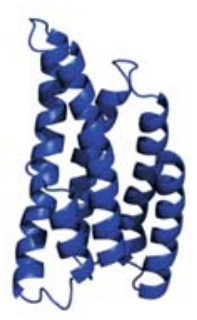

Cog2

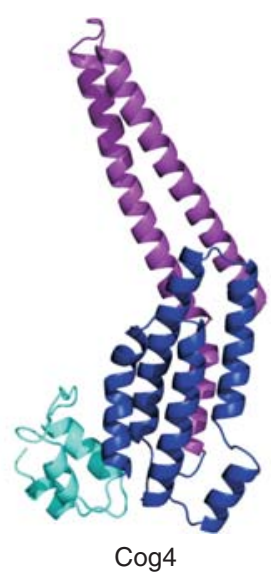

B

Figure 2. Structures of CATCHR subunit domains. (A) Domains of the GARP subunits Vps53 (PDBID 3NS4) and Vps54 (PDBID 3N1E), and of the COG subunits Cog2 (PDBID 2JQQ) and Cog4 (PDBID 3HR0). Proteins were aligned with their central helical-rod domain (blue), with amino-terminal (purple), and carboxy-terminal (cyan) extensions. (B) A short helical peptide from Vps51 of the GARP complex (blue) bound to the Habc domain of the t-SNARE Tgl1 (yellow) (PDBID 2C5K). 
human Vps52 interacts with Rab6 (Liewen et al. 2005).

The COG complex is essential for proper retrograde transport to the early Golgi. COG contains eight subunits (Cog1-8) (Oka et al. 2005) and is localized to the tips and rims of the Golgi cisternae and also to vesicular and tubular structures at the cis- and trans-Golgi network. COG interacts with p115, which is required for Golgi integrity, Ypt1 in its GTP-bound form, the Golgi t-SNARE Syntaxin $5 \mathrm{a} / \mathrm{Sed} 5$, the v-SNAREs GS15 and GS28, as well as the $\gamma$-subunit of COP I (Suvorova et al. 2002; Oka et al. 2004; Zolov and Lupashin 2005; Vasile et al. 2006; Shestakova et al. 2007). Several mutations in COG genes lead to congenital disorder of glycosylation (CDG), in which COG is necessary for the proper recycling of Golgi glycosyltransferases required for normal glycosylation (see Foulquier 2009 for a review).

The crystal structures of two COG subunit domains, of $\operatorname{Cog} 2$ (Cavanaugh et al. 2007) and Cog4 (Richardson et al. 2009), unambiguously identify $\operatorname{Cog}$ as a member of the CATCHR family of tethers (Fig. 2A). Interestingly, the carboxy-terminal fragment of $\operatorname{Cog} 4$ that was crystallized contains the residue arginine 729 that is mutated to tryptophan in patients with CDG. R729 is part of a salt bridge interaction network that stabilizes the helical bundle structure of the protein. Because this domain of the protein is not required in complex formation, its role is probably in mediating association with binding partners of COG (Richardson et al. 2009).

Based on interaction studies of COG subunits in yeast and functional differences caused by the loss of COG components, the COG proteins form two subcomplexes, termed "lobes." Subunits $\operatorname{Cog} 1-4$ form one subcomplex, the "A lobe," and are all essential for cell growth (Oka et al. 2005; Lees et al. 2010); a second subcomplex, the "B lobe," consists of Cog5-8. Interestingly, mutations in genes from the two lobes lead to distinct phenotypes in yeast (Whyte and Munro 2001) and distinguishable effects on glycosylation in mammalian cells (Oka et al. 2005). The mapping of intracomplex interactions confirmed this model, placing $\operatorname{Cog} 1$ at the center of the complex where it connects both lobes (Fotso et al. 2005; Loh and Hong 2004). The two subcomplexes might be involved in the tethering of vesicles from different compartments, mainly from the Golgi but also from endosomes. The bilobal model for COG assembly was supported by cryo-EM studies of crosslinked, purified bovine COG (Ungar et al. 2002). However, more recent studies of reconstituted yeast lobe A $(\operatorname{Cog} 1-4)$, in which the COG subunits were not cross-linked, suggest that the bilobal structure observed in the earlier work is probably an artifact of the crosslinking procedure (Lees et al. 2010). The EM class averages of reconstituted $\operatorname{Cog} 1-4$ show that the subcomplex adopts an extended Yshape and is not globular (Fig. 3A). The position and orientation of the subunits within the complex were determined, showing that the proteins interact via their amino termini and that the carboxyl termini, probably folded into helical-rods, form the "legs" of the complex. The mode of interaction in the amino termini might be through coiled-coil interactions, where each subunit contributes at least one helix. This model is compelling because the CATCHR family was originally identified by the conserved coiled-coil motif putatively present in many of its proteins, tempting the speculation that these motifs mediate complex assembly in all CATCHR complexes. But it is still unclear whether the interactions in $\operatorname{Cog} 1-4$ are coiled-coil interactions and whether the other CATCHR complexes will be assembled similarly. In the Dsll complex, two of its three subunits belong to the CATCHR family, and these two subunits associate via their amino-terminal $\alpha$-helices, which are antiparallel (Fig. 3B) but do not pack as coiled-coils (Tripathi et al. 2009). The overall organization of the Dsll subunits differs from that in $\operatorname{Cog} 1-4$, suggesting that at least Dsl1 and COG are assembled differently. Structural studies of other CATCHR assemblies are still ongoing.

Although the structural studies provided a great deal of information on the architecture of CATCHR complexes, our mechanistic 
A

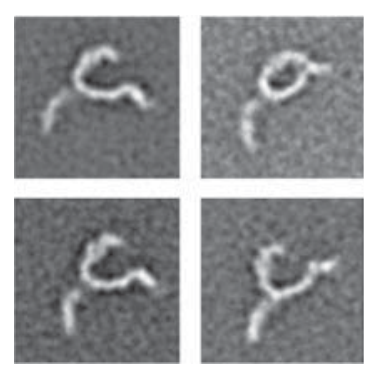

$\operatorname{Cog} 1-4$
B

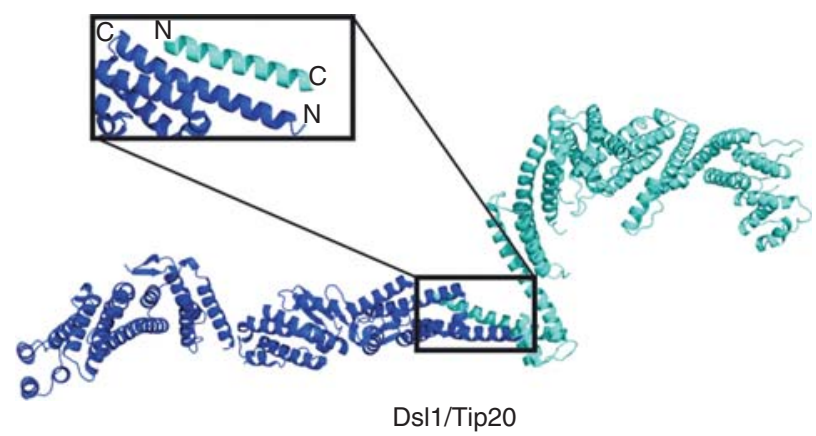

C
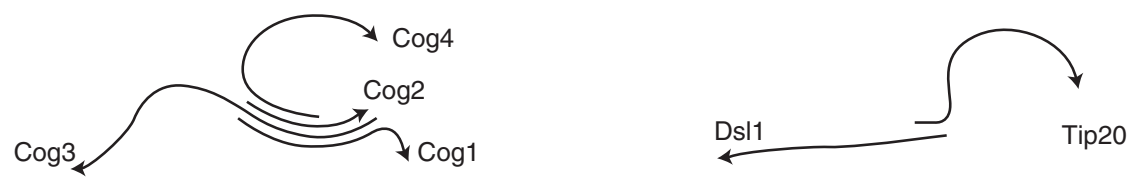

Figure 3. CATCHR subcomplexes. (A) EM class average of the COG1-4 subcomplex (courtesy of T. Walz). (B) The Dsl1/Tip20 subcomplex of the DSL complex (PDBIDs 3ETV, 3K8P, 3FHN). The inserts show the antiparallel association of the amino-terminal helices of the proteins that mediate heterodimerization. $(C)$ Schematic representation of the subunit orientation within the complexes with arrows heads marking the carboxyl terminus.

understanding is still limited. The multilegged, extended tertiary arrangement of COG and presumably other CATCHR complexes (Dong et al. 2005; Munson and Novick 2006; Ren et al. 2009; Lees et al. 2010) suggests several models.

In one model, to tether the vesicles to the Golgi, the complexes are anchored with at least one leg on the Golgi whereas other legs extend away to capture incoming vesicles. The reach of the Cog $1-4$ complex is $\sim 30 \mathrm{~nm}$, consistent with such a tethering function (Pfeffer 1999). Given the considerable flexibility observed for CATCHR assemblies (Hsu et al. 1998; Ren et al. 2009; Lees et al. 2010) it is also plausible that conformational changes in these complexes might aid the transition from vesicle capture to docking and/or fusion (Munson and Novick 2006; Ren et al. 2009).

It is worth noting that the $\operatorname{Cog} 1-4$ assembly binds the t-SNARE Syntaxin 5 at its center where the legs meet, so that if the complex does extend from the Golgi, the Syntaxin5 SNARE motif would have to be in its unfolded state in order for the SNARE to interact with this binding site. In a second model, the CATCHR complexes would lie flat on the membrane, promoting fusion by organizing the fusion machinery but not as tethers per se.

\section{GOLGI COATS}

The generation of transport vesicles is mediated by coat proteins, which play a role in the recruitment of specific cargo proteins, vesicle budding, and vesicle recognition at the target membrane (McMahon and Mills 2004). At the Golgi, clathrin-coated vesicles mediate exit from the trans-Golgi network. COPI (or coatomer) vesicles are required for retrograde intra-Golgi transport as well as cis-Golgi-to-ER transport. Finally, COPII- coated ER-derived vesicles are recognized at the Golgi.

Vesicle coats have an inner and an outer layer. The inner layer consists of adaptor proteins, which are first recruited to the site of budding through interactions with active Arf GTPases, and subsequently concentrate cargo at these sites through specific interactions with sorting motifs. Cage proteins constitute the outer coat and their ability to oligomerize and thereby encapsulate budding vesicles drives formation of these vesicles and also supports their 
D. Kümmel and K.M. Reinisch

fission. In all known vesicle coats, the cage proteins form a lattice rather than a solid coat, so that the inner coat as well as other proteins at the surface of the vesicle are solvent accessible.

\section{Cage Proteins}

The minimal building block for the clathrin cage consists of a curved $190 \mathrm{kDa}$ heavy chain (CHC) and a $25 \mathrm{kDa}$ light chain (CLC) (Fig. 4A) (Fotin et al. 2004). These heterodimers assemble into a trimer via a central hub region in the $\mathrm{CHC}$ carboxyl terminus, giving clathrin a triskelion shape (Fig. 4B). The clathrin heavy chain is composed of eight clathrin heavy-chain repeats (CHCR) in a right-handed superhelical coil (Ybe et al. 1999). Each CHCR consists of $\sim 145$ residues that form 10 helices arranged in a zig-zag of "helix-turn-helix-loop" hairpin units. Each $\alpha$-hairpin is slightly twisted with respect to the preceding hairpin, and the protein is bent at two positions, termed ankle (see Fig. 4) (between CHCR 2 and 3) and knee (between CHCR 5 and 6). As a result, the CHC overall adopts a curved, slightly screwed conformation. To form a cage, clathrin triskelia interdigitate into a lattice of hexagons and pentagons (Fotin et al. 2004). The arrangement of the $\mathrm{CHC}$ is such that each vertex of the polygons consists of two hub-knee and two knee-ankle segments of $\mathrm{CHC}$, contributed by four different triskelia. The amino terminus of the CHC is composed of a $\beta$-propeller of WD40 repeats (ter Haar et al. 1998), which mediates interactions with accessory factors and the inner coat layer. At the carboxyl
A

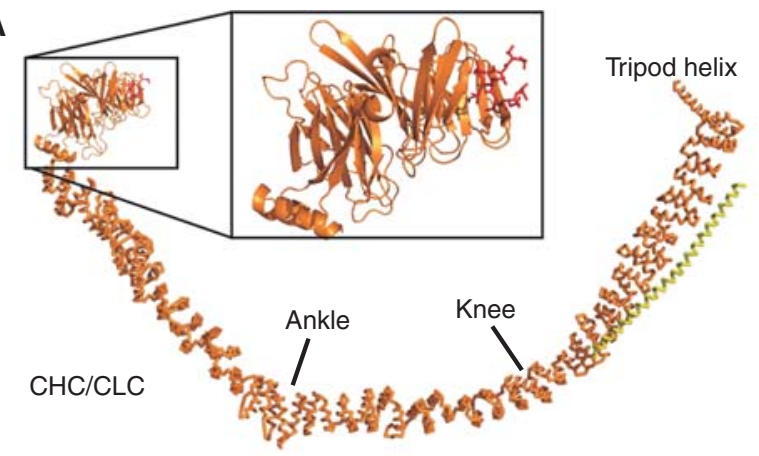

C

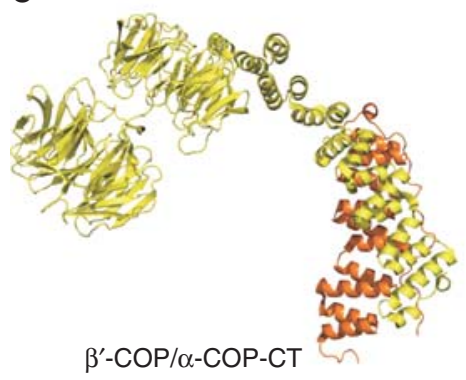

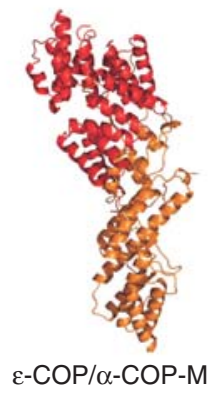

B

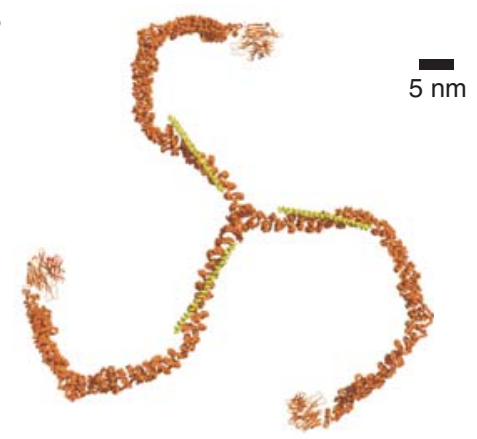

D

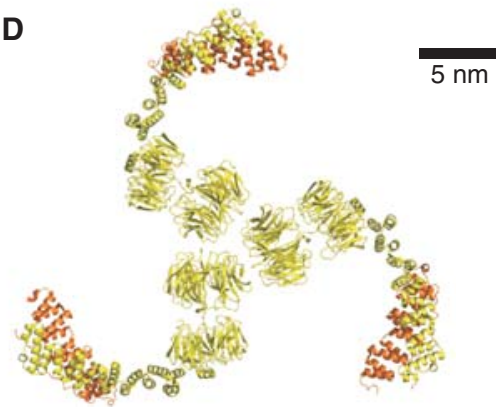

Figure 4. Coat cage protein structures. (A) Clathrin heavy chain ( $\mathrm{CHC}$, orange) and clathrin light chain (CLC, yellow) form an extended $\alpha$-selenoid structure that is bend at a "knee" and "ankle" region (PDBID 1XI4). The amino-terminal WD40 propeller recruits cargo by interacting with the clathrin box motif $\mathrm{L} \phi \mathrm{x} \phi[\mathrm{D} / \mathrm{E}]$ (red, PDBID 1UTC). (B) Triskelion arrangement formed by clathrin. (C) $\beta^{\prime}$-COP (yellow) consists of aminoterminal tandem WD40 domains followed by an $\alpha$-selenoid that interacts with $\alpha$-COP carboxyl terminus (orange, PDBID 3MKQ). The middle portion of $\alpha$-COP (orange) binds to $\varepsilon$-COP (red, PDBID 3MKR). (D) Trimeric crystal packing of $\alpha / \beta^{\prime}$-COP. 
terminus, a long helix extends toward the center of the cage and forms a tripod-like arrangement. The tip of the tripod contacts the ankle regions of interdigitated triskelia, thus strengthening the coat assembly. The CLC aligns along the $\mathrm{CHC}$ near the central hub on the outside of the cage (Fotin et al. 2004; Wilbur et al. 2010), forming an extended helix with short interruptions. It can undergo conformational changes and thereby modulate bending in the CHC knee region (Wilbur et al. 2010). As a consequence, clathrin can switch between a straightened and a curved conformation, and only the curved conformer is capable of efficient coat assembly. This finding suggests a regulatory role for the CLC in coat formation.

The cage of the COPI coat is formed by the coatomer B-subcomplex containing three subunits: $\alpha$-COP, $\beta^{\prime}$-COP, and $\varepsilon$-COP. Recent structures of $\alpha / \beta^{\prime}$-COP (Lee and Goldberg 2010) and $\alpha / \varepsilon-C O P$ (Hsia and Hoelz 2010; Lee and Goldberg 2010) subcomplexes have provided first insights regarding COPI cage assembly. The almost full-length construct of $\beta^{\prime}$-COP used for crystallization contains two aminoterminal seven-blade WD40 $\beta$-propeller domains that are arranged in tandem. These domains are followed by an $\alpha$-solenoid region, which binds to the $\alpha$-solenoid domain in the center of $\alpha$-COP (Fig. 4C). The carboxyl terminus of $\alpha$-COP was crystallized in complex with $\varepsilon$-COP, which folds into tetratricopeptide repeat (TPR) superhelix that caps off $\alpha$-COP. The $\alpha$-COP carboxy-terminal fragment consists of another $\alpha$-solenoid abutted by a fourstranded $\beta$-sheet. A long $\beta$-hairpin emanating from the $\alpha$-solenoid portion is deeply inserted into $\varepsilon$-COP and was therefore termed domain invasion motif (DIM) (Hsia and Hoelz 2010).

The amino terminus of $\alpha$-COP is the only part of the coatomer B-subcomplex that has not been structurally characterized. It is predicted to contain another WD40 propeller domain and an $\alpha$-solenoid region and-in analogy to the Sec13/31 subunits of the COPII coat (Fath et al. 2007)—probably is a further extension of the legs of $\alpha / \beta^{\prime}$-COP.

Interestingly, the $\alpha / \beta^{\prime}$-COP complex trimerizes in the crystal via interactions of the
$\beta^{\prime}$-COP amino-terminal $\beta$-propeller domains (Fig. 4D). Although this interaction has not been observed outside the crystal, it has been speculated that the threefold interface might represent a vertex of the COPI cage and that, as for the clathrin cage, a triskelion may be the physiological assembly unit (Lee and Goldberg 2010). This notion is appealing because the inner coat layers of coatomer and clathrin are thought to be similar (discussed below). Several observations are of note in this context, however. First, the topology of the COPI cage complex more closely resembles that observed for the COPII proteins Sec13 and Sec31 (Fath et al. 2007) than for clathrin, in that the Sec13/31 heterodimer features two tandem $\beta$-propeller domains at one end abutting an $\alpha$-solenoid. And second, the organization of the COPII cage is entirely distinct from that of clathrin, and does not rely on the formation of a triskelion (Stagg et al. 2008). In COPII, the physiological assembly unit is a heterotetramer, consisting of two Sec13/Sec31 complexes that form a rod, with $\beta$-propeller domains placed at the ends. Four, not three, of these rods are arranged around each coat vertex, associated via $\beta$-propeller domains rather than, as in clathrin, the $\alpha$-solenoid domains. Given the similarity in the topology of the cage subunits, it would not be entirely surprising if the organization of the COPI cage turns out to be more similar to that of COPII rather than clathrin. Finally, $\alpha / \beta^{\prime}-\mathrm{COP}$ is also more similar to COPII than to clathrin in dimension (note the scale bars in Fig. 4).

\section{Inner Coat Layer}

The cage complexes are attached to the vesicle by inner coat protein complexes. Clathrin binds to large variety of clathrin adaptor protein complexes, more than 20 in total. Adaptor complexes of the trans-Golgi are AP-1 (Ahle et al. 1988), AP-4 (Dell'Angelica et al. 1999; Hirst et al. 1999) and the Golgi-localized $\gamma$-earcontaining Arf-binding proteins (GGA 1-3) (Boman et al. 2000; Dell'Angelica et al. 2000a; Hirst et al. 2000; Poussu et al. 2000; Takatsu et al. 2000). Like most clathrin adaptors, these 
complexes bind the $\beta$-propeller domain of the CHC through short peptide motifs, the so-called Clathrin box, that are located in an extended disordered region. The clathrin box (Dell'Angelica et al. 1998) has the sequence requirement $\mathrm{L} \phi x \phi[\mathrm{D} / \mathrm{E}]$ ( $\phi$ represents bulky hydrophobic residue L, I, M, F, or V). The crystal structures of the clathrin box from $\beta$-arrestin2 and the $\beta$-subunit of AP-3 show how this motif interacts with a groove between two blades of the CHC WD40 $\beta$-propeller (Fig. 4A) (ter Haar et al. 1998).

The adaptor protein (AP) complexes share a common tetrameric architecture but differ in their composition, containing different subunit isoforms (adaptins). Four subunits interact to form a trunk, composed two large 110$130 \mathrm{kDa}$ subunits $\beta$ and $\alpha, \gamma, \delta$, or $\varepsilon$-which also contain $\gamma$-ear appendages flexibly linked to their trunk domains (see below)-one medium $50 \mathrm{kDa}$ subunit $\mu$, and one small $15-20 \mathrm{kDa}$ subunit $\sigma$ (Fig. 5A). The main differences between the isoforms that constitute the AP complexes are in their specificity for binding partners. The dileucine-based sorting signal $([\mathrm{D} / \mathrm{E}] \mathrm{xxxL}[\mathrm{L} / \mathrm{I}])$ for clathrin cargo (Aiken et al. 1994) is recognized by all AP complexes through a split binding pocket between the $\sigma$ and large $\alpha / \gamma / \delta / \varepsilon$ subunits. In addition, the $\mu$ subunits recognize an alternative tyrosine-based sorting signal $\operatorname{Yxx} \phi$ ( $\phi$ represents bulky hydrophobic residue L, I, M, F, or V) (Ohno et al. 1995). Biochemical studies have shown that binding sites of distinct complexes provide specificity for different dileucine signals (Mattera et al. 2010). Further, the different adaptin complexes bind different phosphoinositide lipids as a prerequisite for their distinct localization. AP-2 binds to $\operatorname{PtdIns}(4,5) \mathrm{P}_{2}$ and $\operatorname{PtdIns}(3,4,5) \mathrm{P} 3$ at the plasma membrane, whereas the AP1 complex binds to the Golgilocalized PtdIns(4)P (Ghosh and Kornfeld 2003). However, the overall architecture and location of phosphoinositide binding sites on the complexes are thought to be similar. Of all adaptin complexes, the structure of the endocytic AP-2 complex (Fig. 5A) has been studied most extensively (Collins et al. 2002; Kelly et al. 2008; Jackson et al. 2010). In the light of the structural similarity to AP-1 (Heldwein et al. 2004), the principles deducted from these studies and discussed below are thought to hold true for all APs.

The large adaptin subunits are structurally related, all forming an $\alpha$-solenoid. $\sigma$-adaptin and the amino-terminal domain of $\mu$-adaptin both adopt the longin fold, a domain that is found widely in transport-related proteins (Fig. 5A) (Collins et al. 2002). The $\alpha$-solenoids in the two large subunits each contribute a half circle to wrap around the longin domains that are in the center of the complex, giving the complex the overall shape of a basket. In the closed, cytosolic from of AP-2, the carboxy-terminal domain of $\mu$-adaptin, which forms an elongated $\beta$-sheet structure, lies in the shallow depression formed by the trunk subunits. The binding sites on AP-2 for the endocytic cargo motifs in the $\mu$-adaptin carboxy-terminal domain $(\operatorname{Yxx} \phi)$ and in $\sigma$-adaptin ([E/ $\mathrm{D}] \mathrm{xxxL}[\mathrm{L} / \mathrm{I}])$ are partially blocked. Also, the binding sites of $\alpha$-adaptin and $\mu$-adaptin are located on different faces of the complex, indicating that this conformation is not active in mediating cargo recruitment and budding.

By cocrystallizing the AP complex with a 70-fold molar access of endocytic tyrosinebased sorting peptide, it was possible to drive the complex into its open, sorting-active state (Fig. 5A) (Jackson et al. 2010). The complex undergoes large structural rearrangements; most prominently, the $\mu$-adaptin carboxyterminal domain moves about $130^{\circ}$ and $40 \AA$, thereby revealing its $\mathrm{Yxx} \phi$ binding pocket. In addition, the $\alpha / \beta / \sigma$-adaptin interface opens up to expose the binding site for dileucine motifs. Strikingly, both endocytic motifbinding sites and four $\operatorname{PtdIns}(4,5) \mathrm{P}_{2}$ pockets are located on the same face of the complex. This arrangement will allow the AP complexes to efficiently interact with membranes and cargo in a cooperative manner, providing an elegant explanation of how sorting and membrane association are coupled.

The large adaptin subunits as well as GGA adaptor proteins contain appendage domains that are connected to their trunk domains by a long flexible linker (Fig. 5B) and function in 
A
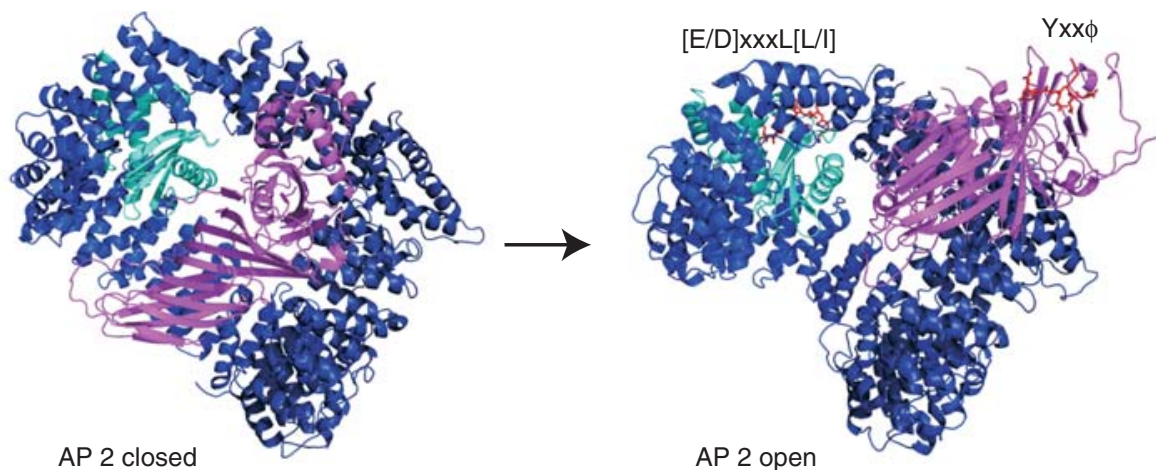

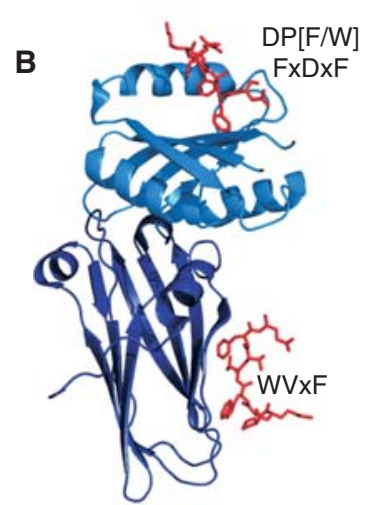

$\alpha$-adaptin/synaptojanin

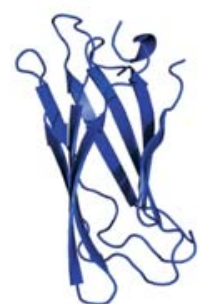

$\gamma$-adaptin

AP 2 open
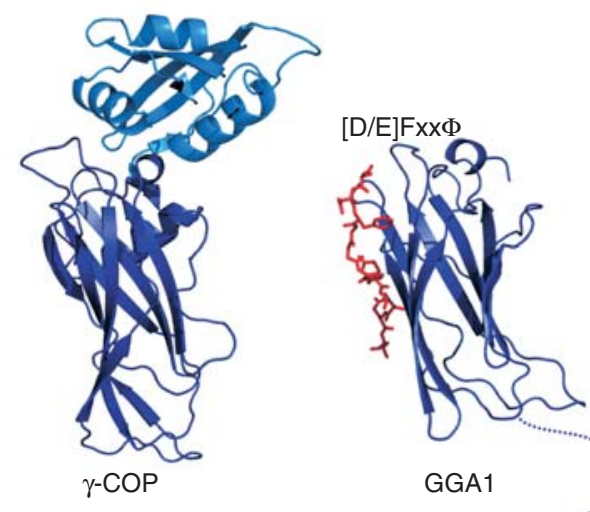

C

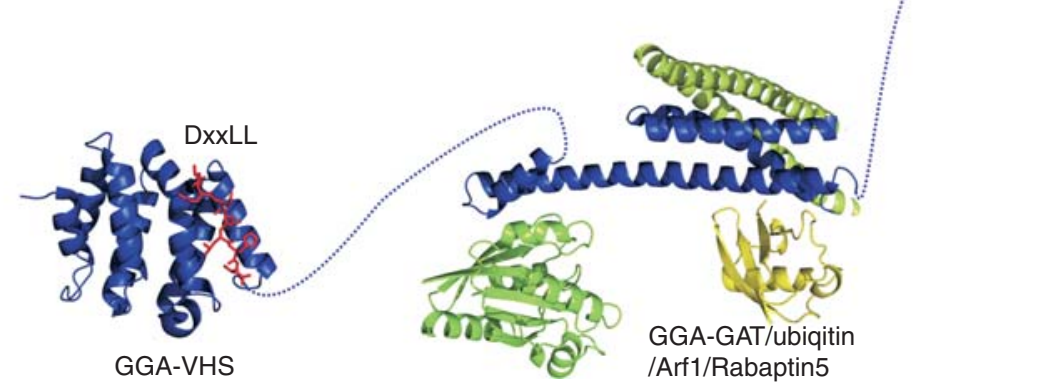

Figure 5. Structures of adaptor proteins. (A) The AP-2 complex, consisting of $\alpha$ - (light blue), $\beta 2$ - (dark blue), $\mu 2$ - (magenta), and $\sigma 2$ - (cyan) adaptin, undergoes large-scale conformational changes during its transition from the closed cytosolic form (PDBID 2VGL) to the open, sorting-active form (PDBID 2XA7). (B) The appendage domains of $\alpha$-adaptin (PDBID 1W80), $\gamma$-adaptin (PDBID 1GYU), $\gamma$-COP (PDBID 1PZD), and GGA1 (1OM9). (C) The VHS domain of GGA1 (PDBID 1JWG) and the GAT domain (PDBID 1NAF) in complex with Arf1 (light green, PDBID 1J2J), ubiquitin (yellow, PDBID 1WR6), and rabaptin5 (dark green, PDBID 1X79). Bound sorting peptides are shown in red as stick representation and are labeled with the corresponding consensus sequence. 
recruiting auxiliary proteins. The structure of the $\alpha 2$-adaptin appendage (Owen et al. 1999; Traub et al. 1999; Brett et al. 2002) consists of an amino-terminal $\beta$-sandwich domain and a carboxy-terminal "platform" domain. The platform domain binds the $\mathrm{DP}[\mathrm{F} / \mathrm{W}]$ peptide motif and $\mathrm{FxDxF}$ motif with an overlapping binding site. In addition, the $\mathrm{WVxF}$ peptide motif is bound by the $\beta$-sandwich domain in a "side" binding pocket (Praefcke et al. 2004). Some appendages lack the platform domain, and only contain the $\beta$-sandwich domain. Members of this class include AP-1 $\gamma$-adaptin (Kent et al. 2002) and the GGA proteins (Miller et al. 2003). These sandwich-only appendages bind to a $[\mathrm{D} /$ E]Fxx $\varphi$ motif ( $\beta$ represents $\mathrm{L} / \mathrm{F} / \mathrm{W} / \mathrm{M}$ ) at a site different from the $\mathrm{WVxF}$ pocket (Collins et al. 2003a).

The GGA adaptors contain, in addition to the carboxy-terminal $\gamma$-ear appendage domains, an amino-terminal VHS (Vps27/Hrs/ Stam) domain and a central GAT (GGA and TOM) domain (Boman et al. 2000; Dell'Angelica et al. 2000a; Hirst et al. 2000; Poussu et al. 2000). The VHS and GAT domains are structurally related to the large trunk subunits of the AP adaptors only in their all $\alpha$-helical fold, but they fulfill an equivalent function, to sort cargo and to mediate membrane association. The three domains of the GGA adaptor proteins are connected by flexible linkers, suggesting that they act as independent units. The hinge region between GAT domain and $\gamma$-ear appendage contains a clathrin box, another similarity to adaptin adaptor organization.

The VHS domain recognizes cargo with an acidic-cluster dileucine (DxxLL) motif, which is found in the cytoplasmic tails of cargo proteins trafficked from the trans-Golgi to the endosomal system (Puertollano et al. 2001a,b; Takatsu et al. 2001; Zhu et al. 2001). The domain consists of eight helices arranged into a right-handed superhelix (Kato et al. 2002; Shiba et al. 2002; Zhu et al. 2003a). The acidic-cluster dileucine motif binds in an extended conformation to a groove between two helices on the surface of the VHS domain (Fig. 5C). The $[\mathrm{E} / \mathrm{D}] \mathrm{xxxL}[\mathrm{L} / \mathrm{I}]$ motif that is recognized by $\sigma$-adaptin, in which the acidic residue is further separated from the dileucine sequence, cannot be accommodated in the binding groove. Interestingly, phosphorylation of a serine residue adjacent to the DxxLL motif can increase the binding affinity to GGA proteins, and GGa1 and 3 contain an internal acidic dileucine motif in their hinge region that can be phopshorylated and act as a regulatable, autoinhibitory ligand for the VHS domain (Doray et al. 2002).

The GAT (GGA and TOM) domain binds Arf1 and Arf3 and thereby mediates recruitment of GGAs to trans-Golgi membranes (Boman et al. 2000; Dell'Angelica et al. 2000b). The GAT domain consists of a threehelical bundle and a short fourth aminoterminal helix, which forms a so-called hook region (Fig. 5C) (Collins et al. 2003b; Shiba et al. 2003; Suer et al. 2003; Zhu et al. 2003b). The Arf GTPases interact with the hook region in a GTP-dependent manner. The three-helix bundle of the GAT domain interacts with the coiled-coil domain of Rabaptin5 (Stenmark et al. 1995; Zhu et al. 2005), an effector of Rab5 in the fusion of early endosomes, and via a different surface binds ubiquitin (Kawasaki et al. 2005; Prag et al. 2005). As with most ubiquitin effectors, the GAT domain interacts with the ubiquitin surface around hydrophobic residue I44. The interactions of GGAs with ubiquitin suggest that GGAs mediate transport of ubiquitinated cargo to endosomes (Puertollano and Bonifacino 2004; Scott et al. 2004).

Only limited structural information for the inner layer of coatomer is available, but sequence analysis suggests that the coatomer F-subcomplex $(\beta$-COP, $\gamma$-COP, $\delta$-COP, and $\varepsilon$-COP subunits) is structurally related to the AP complexes (Schledzewski et al. 1999). It is likely that these COPI subunits form a similar trunk arrangement that serves as cargo adaptor, but will recruit B-coatomer instead of clathrin. $\beta$ - and $\gamma$-COP are also similar to the AP complexes in that they have appendage domains that are connected to their trunk domains by a long flexible linker (Fig. 5B) (Hoffman et al. 2003; Watson et al. 2004). These similarities suggest that coatomer and the clathrin coats are evolutionarily related. 


\section{INTERACTIONS BETWEEN TETHERS AND COATS}

There is a growing body of evidence for communication between the budding and fusion machinery, as evidenced by interactions of golgins, CATCHR complexes, and coats with one another. In particular, Golgin p115 binds to the CATCHR complex COG (Sohda et al. 2007 ) and the $\beta$-subunit of the COPI coat (Guo et al. 2008); the $\varepsilon / \alpha$-subcomplex of COPI interacts with the Dsl1 complex (Hsia and Hoelz 2010); and $\gamma$-COPI binds to COG (Suvorova et al. 2002). The exact role of these interactions, however, remains elusive. Structural characterization of these interactions may be an important step forward as we improve our understanding of the mechanisms that underlie vesicular traffic to/within the Golgi and in general.

\section{REFERENCES}

Ahle S, Mann A, Eichelsbacher U, Ungewickell E. 1988. Structural relationships between clathrin assembly proteins from the Golgi and the plasma membrane. EMBO J 7: 919-929.

Aiken C, Konner J, Landau NR, Lenburg ME, Trono D. 1994. Nef induces CD4 endocytosis: Requirement for a critical dileucine motif in the membrane-proximal CD4 cytoplasmic domain. Cell 76: 853-864.

Allan BB, Moyer BD, Balch WE. 2000. Rab1 recruitment of p115 into a cis-SNARE complex: Programming budding COPII vesicles for fusion. Science 289: 444-448.

An Y, Chen CY, Moyer B, Rotkiewicz P, Elsliger MA, Godzik A, Wilson IA, Balch WE. 2009. Structural and functional analysis of the globular head domain of p115 provides insight into membrane tethering. J Mol Biol 391: 26-41.

Barr FA, Puype M, Vandekerckhove J, Warren G. 1997. GRASP65, a protein involved in the stacking of Golgi cisternae. Cell 91: 253-262.

Barr FA, Nakamura N, Warren G. 1998. Mapping the interaction between GRASP65 and GM130, components of a protein complex involved in the stacking of Golgi cisternae. EMBO J 17: 3258-3268.

Beard M, Satoh A, Shorter J, Warren G. 2005. A cryptic Rab1-binding site in the p115 tethering protein. J Biol Chem 280: 25840-25848.

Bentley M, Liang Y, Mullen K, Xu D, Sztul E, Hay JC. 2006 SNARE status regulates tether recruitment and function in homotypic COPII vesicle fusion. J Biol Chem 281: 38825-38833.

Boman AL, Zhang C, Zhu X, Kahn RA. 2000. A family of ADP-ribosylation factor effectors that can alter membrane transport through the trans-Golgi. Mol Biol Cell 11: $1241-1255$.
Brett TJ, Traub LM, Fremont DH. 2002. Accessory protein recruitment motifs in clathrin-mediated endocytosis. Structure 10: 797-809.

Burguete AS, Fenn TD, Brunger AT, Pfeffer SR. 2008. Rab and Arl GTPase family members cooperate in the localization of the golgin GCC185. Cell 132: 286-298.

Cavanaugh LF, Chen X, Richardson BC, Ungar D, Pelczer I, Rizo J, Hughson FM. 2007. Structural analysis of conserved oligomeric Golgi complex subunit 2. J Biol Chem 282: 23418-23426.

Collins BM, McCoy AJ, Kent HM, Evans PR, Owen DJ. 2002. Molecular architecture and functional model of the endocytic AP2 complex. Cell 109: 523-535.

Collins BM, Praefcke GJ, Robinson MS, Owen DJ. 2003a. Structural basis for binding of accessory proteins by the appendage domain of GGAs. Nat Struct Biol 10: 607-613.

Collins BM, Watson PJ, Owen DJ. 2003b. The structure of the GGA1-GAT domain reveals the molecular basis for ARF binding and membrane association of GGAs. Dev Cell 4: 321-332.

Conibear E, Stevens TH. 2000. Vps52p, Vps53p, and Vps54p form a novel multisubunit complex required for protein sorting at the yeast late Golgi. Mol Biol Cell 11: 305-323.

Conibear E, Cleck JN, Stevens TH. 2003. Vps51p mediates the association of the GARP (Vps52/53/54) complex with the late Golgi t-SNARE Tlg1p. Mol Biol Cell 14: 1610-1623.

Dell'Angelica EC, Klumperman J, Stoorvogel W, Bonifacino JS. 1998. Association of the AP-3 adaptor complex with clathrin. Science 280: 431-434.

Dell'Angelica EC, Mullins C, Bonifacino JS. 1999. AP-4, a novel protein complex related to clathrin adaptors. J Biol Chem 274: 7278-7285.

Dell'Angelica EC, Aguilar RC, Wolins N, Hazelwood S, Gahl WA, Bonifacino JS. 2000a. Molecular characterization of the protein encoded by the Hermansky-Pudlak syndrome type 1 gene. J Biol Chem 275: 1300-1306.

Dell'Angelica EC, Puertollano R, Mullins C, Aguilar RC, Vargas JD, Hartnell LM, Bonifacino JS. 2000b. GGAs: A family of ADP ribosylation factor-binding proteins related to adaptors and associated with the Golgi complex. J Cell Biol 149: 81-94.

Derby MC, Lieu ZZ, Brown D, Stow JL, Goud B, Gleeson PA. 2007. The trans-Golgi network golgin, GCC185, is required for endosome-to-Golgi transport and maintenance of Golgi structure. Traffic 8: 758-773.

Diao A, Rahman D, Pappin DJ, Lucocq J, Lowe M. 2003. The coiled-coil membrane protein golgin-84 is a novel rab effector required for Golgi ribbon formation. J Cell Biol 160: $201-212$.

Dong G, Hutagalung AH, Fu C, Novick P, Reinisch KM. 2005. The structures of exocyst subunit Exo70p and the Exo84p C-terminal domains reveal a common motif. Nat Struct Mol Biol 12: 1094-1100.

Doray B, Bruns K, Ghosh P, Kornfeld SA. 2002. Autoinhibition of the ligand-binding site of GGA1/3 VHS domains by an internal acidic cluster-dileucine motif. Proc Natl Acad Sci 99: 8072-8077.

Drin G, Casella JF, Gautier R, Boehmer T, Schwartz TU, Antonny B. 2007. A general amphipathic $\alpha$-helical motif 
for sensing membrane curvature. Nat Struct Mol Biol 14: $138-146$.

Drin G, Morello V, Casella JF, Gounon P, Antonny B. 2008. Asymmetric tethering of flat and curved lipid membranes by a golgin. Science 320: 670-673.

Fath S, Mancias JD, Bi X, Goldberg J. 2007. Structure and organization of coat proteins in the COPII cage. Cell 129: $1325-1336$.

Feinstein TN, Linstedt AD. 2008. GRASP55 regulates Golgi ribbon formation. Mol Biol Cell 19: 2696-2707.

Fotin A, Cheng Y, Sliz P, Grigorieff N, Harrison SC, Kirchhausen T, Walz T. 2004. Molecular model for a complete clathrin lattice from electron cryomicroscopy. Nature 432: $573-579$.

Fotso P, Koryakina Y, Pavliv O, Tsiomenko AB, Lupashin VV. 2005. Coglp plays a central role in the organization of the yeast conserved oligomeric Golgi complex. J Biol Chem 280: 27613-27623.

Foulquier F. 2009. COG defects, birth and rise! Biochim Biophys Acta 1792: 896-902.

Fridmann-Sirkis Y, Kent HM, Lewis MJ, Evans PR, Pelham HR. 2006. Structural analysis of the interaction between the SNARE Tlg1 and Vps51. Traffic 7: 182-190.

Ghosh P, Kornfeld S. 2003. AP-1 binding to sorting signals and release from clathrin-coated vesicles is regulated by phosphorylation. J Cell Biol 160: 699-708.

Gillingham AK, Tong AH, Boone C, Munro S. 2004. The GTPase Arflp and the ER to Golgi cargo receptor Erv14p cooperate to recruit the golgin Rud3p to the cisGolgi. J Cell Biol 167: 281-292.

Guo Y, Punj V, Sengupta D, Linstedt AD. 2008. Coat-tether interaction in Golgi organization. Mol Biol Cell 19: 2830-2843.

Hayes GL, Brown FC, Haas AK, Nottingham RM, Barr FA, Pfeffer SR. 2009. Multiple Rab GTPase binding sites in GCC185 suggest a model for vesicle tethering at the transGolgi. Mol Biol Cell 20: 209-217.

Heldwein EE, Macia E, Wang J, Yin HL, Kirchhausen T, Harrison SC. 2004. Crystal structure of the clathrin adaptor protein 1 core. Proc Natl Acad Sci 101: 14108-14113.

Hirst J, Bright NA, Rous B, Robinson MS 1999. Characterization of a fourth adaptor-related protein complex. Mol Biol Cell 10: 2787-2802.

Hirst J, Lui WW, Bright NA, Totty N, Seaman MN, Robinson MS. 2000. A family of proteins with $\gamma$-adaptin and VHS domains that facilitate trafficking between the transGolgi network and the vacuole/lysosome. J Cell Biol 149: $67-80$.

Hoffman GR, Rahl PB, Collins RN, Cerione RA. 2003. Conserved structural motifs in intracellular trafficking pathways: structure of the $\gamma \mathrm{COP}$ appendage domain. Mol Cell 12: 615-625.

Houghton FJ, Chew PL, Lodeho S, Goud B, Gleeson PA. 2009. The localization of the Golgin GCC185 is independent of Rab6A/A' and Arl1. Cell 138: 787-794.

Hsia KC, Hoelz A. 2010. Crystal structure of $\alpha$-COP in complex with $\varepsilon$-COP provides insight into the architecture of the COPI vesicular coat. Proc Natl Acad Sci 107: 11271-11276.

Hsu SC, Hazuka CD, Roth R, Foletti DL, Heuser J, Scheller RH. 1998. Subunit composition, protein interactions, and structures of the mammalian brain sec $6 / 8$ complex and septin filaments. Neuron 20: 1111-1122.

Jackson LP, Kelly BT, McCoy AJ, Gaffry T, James LC, Collins BM, Honing S, Evans PR, Owen DJ. 2010. A large-scale conformational change couples membrane recruitment to cargo binding in the AP2 clathrin adaptor complex. Cell 141: 1220-1229.

Kato Y, Misra S, Puertollano R, Hurley JH, Bonifacino JS. 2002. Phosphoregulation of sorting signal-VHS domain interactions by a direct electrostatic mechanism. Nat Struct Biol 9: 532-536.

Kawasaki M, Shiba T, Shiba Y, Yamaguchi Y, Matsugaki N, Igarashi N, Suzuki M, Kato R, Kato K, Nakayama K, et al. 2005. Molecular mechanism of ubiquitin recognition by GGA3 GAT domain. Genes Cells 10: 639-654.

Kelly BT, McCoy AJ, Spate K, Miller SE, Evans PR, Honing S, Owen DJ. 2008. A structural explanation for the binding of endocytic dileucine motifs by the AP2 complex. Nature 456: 976-979.

Kent HM, McMahon HT, Evans PR, Benmerah A, Owen DJ. 2002. $\gamma$-adaptin appendage domain: structure and binding site for Eps15 and $\gamma$-synergin. Structure 10: 1139-1148.

Kuo A, Zhong C, Lane WS, Derynck R. 2000. Transmembrane transforming growth factor- $\alpha$ tethers to the PDZ domain-containing, Golgi membrane-associated protein p59/GRASP55. EMBO J 19: 6427-6439.

Lee C, Goldberg J. 2010. Structure of coatomer cage proteins and the relationship among COPI, COPII, and clathrin vesicle coats. Cell 142: 123-132.

Lees JA, Yip CK, Walz T, Hughson FM. 2010. Molecular organization of the COG vesicle tethering complex. Nat Struct Mol Biol 17: 1292-1297.

Levine TP, Rabouille C, Kieckbusch RH, Warren G. 1996. Binding of the vesicle docking protein p115 to Golgi membranes is inhibited under mitotic conditions. $J$ Biol Chem 271: 17304-17311.

Liewen H, Meinhold-Heerlein I, Oliveira V, Schwarzenbacher R, Luo G, Wadle A, Jung M, Pfreundschuh M, Stenner-Liewen F. 2005. Characterization of the human GARP (Golgi associated retrograde protein) complex. Exp Cell Res 306: 24-34.

Linstedt AD, Hauri HP. 1993. Giantin, a novel conserved Golgi membrane protein containing a cytoplasmic domain of at least $350 \mathrm{kDa}$. Mol Biol Cell 4: 679-693.

Linstedt AD, Jesch SA, Mehta A, Lee TH, Garcia-Mata R, Nelson DS, Sztul E. 2000. Binding relationships of membrane tethering components. The giantin $\mathrm{N}$ terminus and the GM130 N terminus compete for binding to the p115 C terminus. J Biol Chem 275: 10196-10201.

Loh E, Hong W. 2004. The binary interacting network of the conserved oligomeric Golgi tethering complex. J Biol Chem 279: 24640-24648.

Mattera R, Boehm M, Chaudhuri R, Prabhu Y, Bonifacino JS. 2010. Conservation and diversification of dileucine signal recognition by adaptor protein (AP) complex variants. J Biol Chem 286: 2022-2030.

McMahon HT, Mills IG. 2004. COP and clathrin-coated vesicle budding: Different pathways, common approaches. Curr Opin Cell Biol 16: 379-391. 
Miller GJ, Mattera R, Bonifacino JS, Hurley JH. 2003. Recognition of accessory protein motifs by the $\gamma$-adaptin ear domain of GGA3. Nat Struct Biol 10: 599-606.

Munson M, Novick P. 2006. The exocyst defrocked, a framework of rods revealed. Nat Struct Mol Biol 13: 577-581.

Nakamura N, Lowe M, Levine TP, Rabouille C, Warren G. 1997. The vesicle docking protein p115 binds GM130, a cis-Golgi matrix protein, in a mitotically regulated manner. Cell 89: 445-455.

Ohno H, Stewart J, Fournier MC, Bosshart H, Rhee I, Miyatake S, Saito T, Gallusser A, Kirchhausen T, Bonifacino JS. 1995. Interaction of tyrosine-based sorting signals with clathrin-associated proteins. Science 269: 1872-1875.

Oka T, Ungar D, Hughson FM, Krieger M. 2004. The COG and COPI complexes interact to control the abundance of GEARs, a subset of Golgi integral membrane proteins. Mol Biol Cell 15: 2423-2435.

Oka T, Vasile E, Penman M, Novina CD, Dykxhoorn DM, Ungar D, Hughson FM, Krieger M. 2005. Genetic analysis of the subunit organization and function of the conserved oligomeric golgi (COG) complex: Studies of COG5- and COG7-deficient mammalian cells. J Biol Chem 280: 32736-32745.

Owen DJ, Vallis Y, Noble ME, Hunter JB, Dafforn TR, Evans PR, McMahon HT. 1999. A structural explanation for the binding of multiple ligands by the $\alpha$-adaptin appendage domain. Cell 97: 805-815.

Panic B, Perisic O, Veprintsev DB, Williams RL, Munro S. 2003a. Structural basis for Arl1-dependent targeting of homodimeric GRIP domains to the Golgi apparatus. Mol Cell 12: 863-874.

Panic B, Whyte JR, Munro S. 2003b. The ARF-like GTPases Arllp and Arl3p act in a pathway that interacts with vesicle-tethering factors at the Golgi apparatus. Curr Biol 13: 405-410.

Perez-Victoria FJ, Abascal-Palacios G, Tascon I, Kajava A, Magadan JG, Pioro EP, Bonifacino JS, Hierro A. 2010a. Structural basis for the wobbler mouse neurodegenerative disorder caused by mutation in the Vps54 subunit of the GARP complex. Proc Natl Acad Sci 107: 1286012865.

Perez-Victoria FJ, Schindler C, Magadan JG, Mardones GA, Delevoye C, Romao M, Raposo G, Bonifacino JS. 2010b. Ang2/fat-free is a conserved subunit of the Golgi-associated retrograde protein complex. Mol Biol Cell 21: 33863395.

Pfeffer SR. 1999. Transport-vesicle targeting: Tethers before SNAREs. Nat Cell Biol 1: E17-E22.

Poussu A, Lohi O, Lehto VP. 2000. Vear, a novel Golgiassociated protein with VHS and $\gamma$-adaptin "ear" domains. J Biol Chem 275: 7176-7183.

Praefcke GJ, Ford MG, Schmid EM, Olesen LE, Gallop JL, Peak-Chew SY, Vallis Y, Babu MM, Mills IG, McMahon HT. 2004. Evolving nature of the AP2 $\alpha$-appendage hub during clathrin-coated vesicle endocytosis. $E M B O J$ 23: 4371-4383.

Prag G, Lee S, Mattera R, Arighi CN, Beach BM, Bonifacino JS, Hurley JH. 2005. Structural mechanism for ubiquitinated-cargo recognition by the Golgi-localized, $\gamma$-ear-containing, ADP-ribosylation-factor-binding proteins. Proc Natl Acad Sci 102: 2334-2339.
Puertollano R, Bonifacino JS (2004). Interactions of GGA3 with the ubiquitin sorting machinery. Nat Cell Biol 6: 244-251.

Puertollano R, Aguilar RC, Gorshkova I, Crouch RJ, Bonifacino JS. 2001a. Sorting of mannose 6-phosphate receptors mediated by the GGAs. Science 292: $1712-$ 1716.

Puertollano R, Martinez-Menarguez JA, Batista A, Ballesta J, Alonso MA. 2001b. An intact dilysine-like motif in the carboxyl terminus of MAL is required for normal apical transport of the influenza virus hemagglutinin cargo protein in epithelial Madin-Darby canine kidney cells. Mol Biol Cell 12: 1869-1883.

Ren Y, Yip CK, Tripathi A, Huie D, Jeffrey PD, Walz T, Hughson FM. 2009. A structure-based mechanism for vesicle capture by the multisubunit tethering complex Dsl1. Cell 139: 1119-1129.

Richardson BC, Smith RD, Ungar D, Nakamura A, Jeffrey PD, Lupashin VV, Hughson FM. 2009. Structural basis for a human glycosylation disorder caused by mutation of the COG4 gene. Proc Natl Acad Sci 106: 13329-13334.

Sapperstein SK, Walter DM, Grosvenor AR, Heuser JE, Waters MG. 1995. p115 is a general vesicular transport factor related to the yeast endoplasmic reticulum to Golgi transport factor Usolp. Proc Natl Acad Sci 92: 522-526.

Schledzewski K, Brinkmann H, Mendel RR. 1999. Phylogenetic analysis of components of the eukaryotic vesicle transport system reveals a common origin of adaptor protein complexes 1,2 , and 3 and the F subcomplex of the coatomer COPI. J Mol Evol 48: 770-778.

Schmitt-John T, Drepper C, Mussmann A, Hahn P, Kuhlmann M, Thiel C, Hafner M, Lengeling A, Heimann P, Jones JM, et al. 2005. Mutation of Vps54 causes motor neuron disease and defective spermiogenesis in the wobbler mouse. Nat Genet 37: 1213-1215.

Scott PM, Bilodeau PS, Zhdankina O, Winistorfer SC, Hauglund MJ, Allaman MM, Kearney WR, Robertson AD, Boman AL, Piper RC. 2004. GGA proteins bind ubiquitin to facilitate sorting at the trans-Golgi network. Nat Cell Biol 6: 252-259.

Sengupta D, Linstedt AD. 2010. Mitotic inhibition of GRASP65 organelle tethering involves Polo-like kinase 1 (PLK1) phosphorylation proximate to an internal PDZ ligand. J Biol Chem 285: 39994-40003.

Sengupta D, Truschel S, Bachert C, Linstedt AD. 2009. Organelle tethering by a homotypic PDZ interaction underlies formation of the Golgi membrane network. J Cell Biol 186: 41-55.

Setty SR, Shin ME, Yoshino A, Marks MS, Burd CG. 2003. Golgi recruitment of GRIP domain proteins by Arf-like GTPase 1 is regulated by Arf-like GTPase 3. Curr Biol 13: $401-404$.

Shestakova A, Suvorova E, Pavliv O, Khaidakova G, Lupashin V. 2007. Interaction of the conserved oligomeric Golgi complex with t-SNARE Syntaxin5a/Sed5 enhances intra-Golgi SNARE complex stability. J Cell Biol 179: 1179-1192.

Shiba T, Takatsu H, Nogi T, Matsugaki N, Kawasaki M, Igarashi N, Suzuki M, Kato R, Earnest T, Nakayama K, et al. 2002. Structural basis for recognition of acidic-cluster dileucine sequence by GGA1. Nature 415: 937-941. 
D. Kümmel and K.M. Reinisch

Shiba T, Kawasaki M, Takatsu H, Nogi T, Matsugaki N, Igarashi N, Suzuki M, Kato R, Nakayama K, Wakatsuki S. 2003. Molecular mechanism of membrane recruitment of GGA by ARF in lysosomal protein transport. Nat Struct Biol 10: 386-393.

Short B, Preisinger C, Korner R, Kopajtich R, Byron O, Barr FA. 2001. A GRASP55-rab2 effector complex linking Golgi structure to membrane traffic. J Cell Biol 155: 877-883.

Short B, Haas A, Barr FA. 2005. Golgins and GTPases, giving identity and structure to the Golgi apparatus. Biochim Biophys Acta 1744: 383-395.

Shorter J, Watson R, Giannakou ME, Clarke M, Warren G, Barr FA. 1999. GRASP55, a second mammalian GRASP protein involved in the stacking of Golgi cisternae in a cell-free system. ЕMBO J 18: 4949-4960.

Shorter J, Beard MB, Seemann J, Dirac-Svejstrup AB, Warren G. 2002. Sequential tethering of Golgins and catalysis of SNAREpin assembly by the vesicle-tethering protein 115. J Cell Biol 157: 45-62.

Siniossoglou S, Pelham HR. 2001. An effector of Ypt6p binds the SNARE Tlglp and mediates selective fusion of vesicles with late Golgi membranes. EMBO J 20: 5991-5998.

Siniossoglou S, Pelham HR. 2002. Vps51p links the VFT complex to the SNARE Tlg1p. J Biol Chem 277: 4831848324.

Sinka R, Gillingham AK, Kondylis V, Munro S. 2008. Golgi coiled-coil proteins contain multiple binding sites for Rab family G proteins. J Cell Biol 183: 607-615.

Sohda M, Misumi Y, Yoshimura S, Nakamura N, Fusano T, Ogata S, Sakisaka S, Ikehara Y. 2007. The interaction of two tethering factors, p115 and COG complex, is required for Golgi integrity. Traffic 8: 270-284.

Stagg SM, LaPointe P, Razvi A, Gurkan C, Potter CS, Carragher B, Balch WE. 2008. Structural basis for cargo regulation of COPII coat assembly. Cell 134: 474-484.

Stenmark H, Vitale G, Ullrich O, Zerial M. 1995. Rabaptin-5 is a direct effector of the small GTPase Rab5 in endocytic membrane fusion. Cell 83: 423-432.

Striegl H, Roske Y, Kummel D, Heinemann U. 2009. Unusual armadillo fold in the human general vesicular transport factor 115. PLoS One 4: e4656.

Suer S, Misra S, Saidi LF, Hurley JH. 2003. Structure of the GAT domain of human GGAl: A syntaxin aminoterminal domain fold in an endosomal trafficking adaptor. Proc Natl Acad Sci 100: 4451-4456.

Suvorova ES, Duden R, Lupashin VV. 2002. The Sec34/ Sec35p complex, a Yptlp effector required for retrograde intra-Golgi trafficking, interacts with Golgi SNAREs and COPI vesicle coat proteins. J Cell Biol 157: 631-643.

Takatsu H, Yoshino K, Nakayama K. 2000. Adaptor $\gamma$ ear homology domain conserved in $\gamma$-adaptin and GGA proteins that interact with $\gamma$-synergin. Biochem Biophys Res Commun 271: 719-725.

Takatsu H, Katoh Y, Shiba Y, Nakayama K. 2001. Golgilocalizing, $\gamma$-adaptin ear homology domain, ADP-ribosylation factor-binding (GGA) proteins interact with acidic dileucine sequences within the cytoplasmic domains of sorting receptors through their Vps27p/
Hrs/STAM (VHS) domains. J Biol Chem 276: 2854128545.

ter Haar E, Musacchio A, Harrison SC, Kirchhausen T. 1998. Atomic structure of clathrin: A $\beta$ propeller terminal domain joins an $\alpha$ zigzag linker. Cell 95: 563-573.

Traub LM, Downs MA, Westrich JL, Fremont DH. 1999. Crystal structure of the $\alpha$ appendage of AP-2 reveals a recruitment platform for clathrin-coat assembly. Proc Natl Acad Sci 96: 8907-8912.

Tripathi A, Ren Y, Jeffrey PD, Hughson FM. 2009. Structural characterization of Tip20p and Dsl1p, subunits of the Dsllp vesicle tethering complex. Nat Struct Mol Biol 16: 114-123.

Truschel ST, Sengupta D, Foote A, Heroux A, Macbeth MR, Linstedt AD. 2011. Structure of the membrane tethering GRASP domain reveals a unique PDZ Ligand interaction that mediates Golgi biogenesis. J Biol Chem 23: 20125-20129 2323.

Ungar D, Oka T, Brittle EE, Vasile E, Lupashin VV, Chatterton JE, Heuser JE, Krieger M, Waters MG. 2002. Characterization of a mammalian Golgi-localized protein complex, COG, that is required for normal Golgi morphology and function. J Cell Biol 157: 405-415.

Vasan N, Hutagalung A, Novick P, Reinisch KM. 2010. Structure of a C-terminal fragment of its Vps53 subunit suggests similarity of Golgi-associated retrograde protein (GARP) complex to a family of tethering complexes. Proc Natl Acad Sci 107: 14176-14181.

Vasile E, Oka T, Ericsson M, Nakamura N, Krieger M. 2006. IntraGolgi distribution of the Conserved Oligomeric Golgi (COG) complex. Exp Cell Res 312: 3132-3141.

Wang Y, Satoh A, Warren G. 2005. Mapping the functional domains of the Golgi stacking factor GRASP65. J Biol Chem 280: 4921-4928.

Watson PJ, Frigerio G, Collins BM, Duden R, Owen DJ. 2004. $\gamma$-COP appendage domain - structure and function. Traffic 5: 79-88.

Whyte JR, Munro S. 2001. The Sec34/35 Golgi transport complex is related to the exocyst, defining a family of complexes involved in multiple steps of membrane traffic. Dev Cell 1: 527-537.

Whyte JR, Munro S. 2002. Vesicle tethering complexes in membrane traffic. J Cell Sci 115: 2627-2637.

Wilbur JD, Hwang PK, Ybe JA, Lane M, Sellers BD, Jacobson MP, Fletterick RJ, Brodsky FM. 2010. Conformation switching of clathrin light chain regulates clathrin lattice assembly. Dev Cell 18: 841-848.

Wu M, Lu L, Hong W, Song H. 2004. Structural basis for recruitment of GRIP domain golgin-245 by small GTPase Arll. Nat Struct Mol Biol 11: 86-94.

Xiang Y, Wang Y. 2010. GRASP55 and GRASP65 play complementary and essential roles in Golgi cisternal stacking. J Cell Biol 188: 237-251.

Yamakawa H, Seog DH, Yoda K, Yamasaki M, Wakabayashi T. 1996. Usol protein is a dimer with two globular heads and a long coiled-coil tail. J Struct Biol 116: 356-365.

Ybe JA, Brodsky FM, Hofmann K, Lin K, Liu SH, Chen L, Earnest TN, Fletterick RJ, Hwang PK. 1999. Clathrin selfassembly is mediated by a tandemly repeated superhelix. Nature 399: 371-375. 
Yu IM, Hughson FM. 2010. Tethering factors as organizers of intracellular vesicular traffic. Annu Rev Cell Dev Biol 26: $137-156$.

Zhu Y, Doray B, Poussu A, Lehto VP, Kornfeld S. 2001. Binding of GGA2 to the lysosomal enzyme sorting motif of the mannose 6-phosphate receptor. Science 292: 1716-1718.

Zhu G, He X, Zhai P, Terzyan S, Tang J, Zhang XC. 2003a Crystal structure of GGA2 VHS domain and its implication in plasticity in the ligand binding pocket. FEBS Let 537: $171-176$
Zhu G, Zhai P, He X, Terzyan S, Zhang R, Joachimiak A, Tang J, Zhang XC. 2003b. Crystal structure of the human GGAl GAT domain. Biochemistry 42: 63926399.

Zhu G, Zhai P, Wakeham N, He X, Zhang XC. 2005. Analysis of the interaction between GGAl GAT domain and Rabaptin-5. Methods Enzymol 403: 583-592.

Zolov SN, Lupashin VV. 2005. Cog3p depletion blocks vesicle-mediated Golgi retrograde trafficking in HeLa cells. J Cell Biol 168: 747-759. 


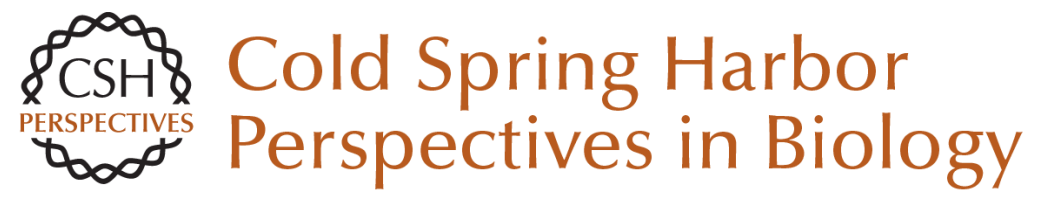

\section{Structure of Golgi Transport Proteins}

Daniel Kümmel and Karin M. Reinisch

Cold Spring Harb Perspect Biol 2011; doi: 10.1101/cshperspect.a007609 originally published online August 2, 2011

\section{Subject Collection The Golgi}

Structure of Golgi Transport Proteins

Daniel Kümmel and Karin M. Reinisch

\section{Golgi Biogenesis}

Yanzhuang Wang and Joachim Seemann

Golgi Glycosylation and Human Inherited

Diseases

Hudson H. Freeze and Bobby G. Ng

Models for Golgi Traffic: A Critical Assessment

Benjamin S. Glick and Alberto Luini

\section{Architecture of the Mammalian Golgi} Judith Klumperman

Evolution and Diversity of the Golgi Mary J. Klute, Paul Melançon and Joel B. Dacks

Evolutionary Forces Shaping the Golgi

Glycosylation Machinery: Why Cell Surface

Glycans Are Universal to Living Cells Ajit Varki

Golgi Positioning

Smita Yadav and Adam D. Linstedt
Golgi and Related Vesicle Proteomics: Simplify to Identify Joan Gannon, John J.M. Bergeron and Tommy Nilsson

Organization of SNAREs within the Golgi Stack Jörg Malsam and Thomas H. Söllner

Golgi during Development Weimin Zhong

Entry and Exit Mechanisms at the cis-Face of the Golgi Complex Andrés Lorente-Rodríguez and Charles Barlowe

COPI Budding within the Golgi Stack Vincent Popoff, Frank Adolf, Britta Brügger, et al.

Mechanisms of Protein Retention in the Golgi David K. Banfield

The Golgin Coiled-Coil Proteins of the Golgi

Apparatus Sean Munro

Signaling at the Golgi Peter Mayinger

For additional articles in this collection, see http://cshperspectives.cshlp.org/cgi/collection/

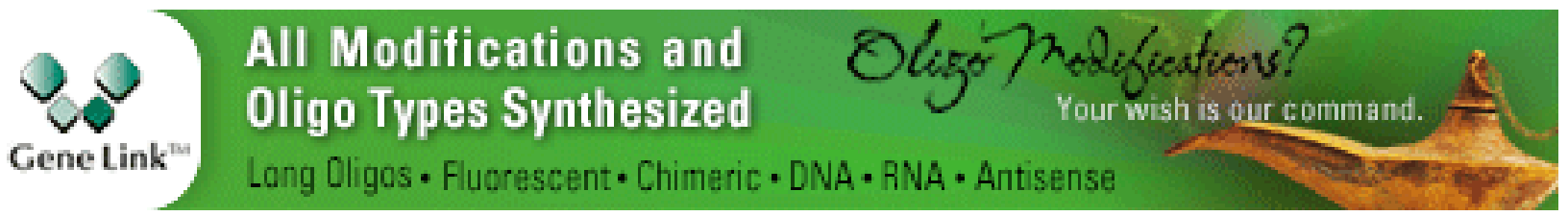

Copyright @ 2011 Cold Spring Harbor Laboratory Press; all rights reserved 